\title{
Governing long-term social-ecological change: What can the resilience and transitions approaches learn from each other?
}

\section{Timothy J. Foxon*, Lindsay C. Stringer and Mark S. Reed}

*Corresponding author

Sustainability Research Institute (SRI),

School of Earth and Environment,

University of Leeds,

Leeds, LS2 9JT, U.K.

E-mail: t.j.foxon@leeds.ac.uk

Telephone: +44 1133437910

Fax: +44 1133436716

Paper prepared for presentation at the 2008 Berlin Conference, 'Long-Term Policies:

Governing Social-Ecological Change', Berlin, 22-23 February 2008 


\title{
Governing long-term social-ecological change: What can the resilience and transitions approaches learn from each other?
}

\begin{abstract}
Addressing challenges of maintaining social welfare and opportunity in the face of severe ecological pressures requires frameworks for addressing and governing long-term social-ecological change. This paper analyses what two recent frameworks could learn from each other. The first aims to understand transitions in socio-technical systems, by analysing dynamic interactions between three levels: niches, socio-technical regimes and landscape. This has led to the concept of transition management as a process of shaping or modulating socio-technical regimes towards long-term sustainability goals. The second focuses on resilience and adaptive capacity, by analysing wider social-ecological systems in terms of their ability to absorb disturbance, self-organise and build and increase the capacity for learning and adaptation. This approach views management interventions as experiments from which successive interventions can be adapted to more effectively manage socio-ecological systems.

Though usually applied in different domains, the two conceptual frameworks share a focus on the ability of systems to learn and develop adaptive capacity whilst facing external shocks and long-term pressures, and aim to integrate bottom-up and top-down approaches. Both frameworks share an emphasis on learning from experimentation in complex systems, but the transitions framework focuses more on the ability to steer long-term changes in system functions, whilst the resilience framework emphasises maintenance of system functions in the face of external change. The combination of iterative learning and stakeholder participation from the resilience framework has the potential to incorporate vital feedbacks into transitions management, which in turn offers a longer-term perspective from which to learn about and manage socio-technical change. The paper argues that by combining insights from both frameworks, it may be possible to foster more robust and resilient governance of social-ecological systems, than could be achieved by either approach alone.
\end{abstract}

\section{Introduction}

Over recent years, the world's policymakers and media have focussed increasing attention on events such as hurricane Katrina (2005), the Pakistan earthquake (2006) and the extensive summer flooding in the UK (2007), together with disease outbreaks such as Foot and Mouth Disease, bluetongue virus and bird flu. Such events emphasise how vulnerable the socio-ecological systems in which we live remain to disturbances (Janssen and Ostrom, 2006). At the same time, these systems face climate change, requiring policymakers, and societies in general, to achieve a transition to a low carbon economy. This will require reductions in global greenhouse gas (GHG) emissions of $50-80 \%$ by 2050 according to the IPCC (2007). Addressing the challenge of maintaining social welfare and opportunity in the face of such pressures requires the ongoing development of appropriate frameworks for managing and governing long-term social-ecological change. While no single governance or management framework is likely to be appropriate under all circumstances (Nagendra, 2007), there is currently a tendency for single, generalised solutions to be prescribed based on simple models of social-ecological systems (Ostrom et al., 2007; Ostrom, 2007). These often neglect to look more broadly across sectors and can lead to the adoption of so-called blue-print or "panacea" policy instruments (Brock and Carpenter, 2007). While several different frameworks may be drawn upon to inform social-ecological policy (for example, OECD's (1993) Pressure-State-ImpactResponse framework; Scoones' (1998) Sustainable Livelihoods Framework; and Bossel's (1998, 2001) Orientation Theory), these often remain restricted to the theoretical, disciplinary and problem base in which they were originally conceived. This results in their rather narrow application and limits the opportunities for one 
framework to inform the development or evolution of another in relation to a different policy sector or management area. In addition, these long-term socio-ecological challenges are characterised by high levels of risk and uncertainty about future social, technical and economic possibilities and outcomes, and governance frameworks need to take these into account.

Two recent frameworks, relating to adaptive management (AM) of socio-ecological systems and transition management (TM) in socio-technical systems, have begun to address key aspects of these challenges, but have largely developed independently and, until very recently, without significant mutual interaction. Of late, it has been suggested that there exists huge potential for learning between the AM and TM frameworks (van der Brugge and van Raak, 2007; Pahl-Wostl, 2007). This paper aims to add to a potentially fruitful dialogue in this area, contributing towards the development of more robust and resilient systems for the governance of socialecological systems.

The first framework we consider (Section 2) aims to understand transitions in sociotechnical systems, by analysing dynamic interactions between three levels: niches, socio-technical regimes and landscape. This has led to the concept of transition management as a process of shaping or modulating socio-technical regimes towards long-term sustainability goals. The second framework (Section 3) focuses on resilience and adaptive capacity, by analysing wider social-ecological systems in terms of their ability to absorb disturbance, self-organise and build and increase the capacity for learning and adaptation. This approach views management interventions as experiments from which successive interventions can be adapted to more effectively manage socio-ecological systems. Although both frameworks broadly stem from complex adaptive system theory (van der Brugge and van Raak, 2007), their domains of application to date have largely differed. We argue (Section 4) that by combining insights from both frameworks, it may be possible to foster more robust and resilient governance of complex social-ecological systems than could be achieved by either framework alone. Indeed, managing for resilience may enhance the possibility of sustaining desirable pathways under conditions of future uncertainty (cf. Walker et al., 2004; Adger et al., 2005).

\section{Transitions and transition management framework}

The ideas of transition management arose out of work on understanding long-term transitions in socio-technical systems, building on insights from a range of literatures on innovation systems, evolutionary economics and social shaping/construction of technological systems (Geels, 2002). A key theoretical step was the formulation of a multi-level framework for understanding such transitions, which analyses dynamic interactions between three levels: niches, socio-technical regimes and landscape (Rip and Kemp, 1998). In response to demands from policy-makers in the Netherlands, it was proposed that this could provide a useful framework for a process of shaping or modulating socio-technical regimes towards long-term sustainability goals, referred to as transition management. In this framework, a socio-technical regime arises through the interaction between the actors and institutions involved in creating and reinforcing a particular technological system and acquires a social stability and resistance to change. As described by Rip and Kemp (1998): “A socio-technical regime is the rule- 
set or grammar embedded in a complex of engineering practices; production process technologies; product characteristics, skills and procedures; ways of handling relevant artefacts and persons; ways of defining problems; all of them embedded in institutions and infrastructures." Landscape represents the broader political, social and cultural values and institutions that form the deep structural relationships of a society, and so are even more resistant to change than regimes. Whereas the existing regime generates incremental innovation, radical innovations are generated in niches. As a regime will usually not be totally homogeneous, niches occur, providing spaces that at least partially insulated from 'normal' market selection in the regime, for example, specialised sectors of the market, or locations where a slightly different institutional rule-set applies.

Transition management was adopted as a policymaking process in the Netherlands, as part of the $4^{\text {th }}$ Netherlands Environmental Policy Plan (NMP4), published in 2000 (see Rotmans et al., 2001; Kemp and Rotmans, 2005). This Plan argued that there remains a set of persistent environmental problems to be addressed: climate change, biodiversity issues, depletion of resources, threats to human health, and that these require a systems approach to policy making, in order to stimulate transitions towards sustainable energy, transport, resource use and agriculture. Following the publication of the NMP4, transition management programmes have been initiated for these four areas by the four Ministries responsible. The 'Energy Transition' programme is following a public-private partnership approach, facilitated by the Ministry of Economic Affairs (Ministry of Economic Affairs, 2006). This has so far involved the formulation of 26 transition paths, from four transition platforms (with the themes 'sustainable mobility', 'new gas and clean fossil fuels', 'green raw materials' and 'chain efficiency'). These paths are based on their contribution to reducing $\mathrm{CO}_{2}$ emissions, the opportunities they offer to Dutch companies and their technological feasibility, as assessed by stakeholders brought together in a transition arena. To facilitate learning-by-doing and to assess these transition paths, a large number of practical transition experiments are being undertaken. These typically involve collaboration between technology developers, industrial partners, local authorities and community groups, and are designed to test the social and technological feasibility and acceptability of the transition paths.

Transition management is thus envisioned as a more process-oriented and goalseeking philosophy designed to deal with complexity and uncertainty in a constructive way. Key elements claimed for transition management are (Loorbach and Rotmans, 2006):

- systems-thinking in terms of a range of actors and sectors interacting at multiple levels;

- long-term thinking (at least 25 years) as a framework for shaping short-term policy;

- back- and fore-casting: setting of short-term and longer-term goals based on long-term sustainability visions, scenario-studies, trend-analyses and shortterm possibilities;

- a focus on learning-by-doing;

- an orientation towards system innovation and experiments;

- learning about a variety of options;

- participation of and interaction between stakeholders. 
The forward-looking and iterative, learning-based approach of transition management is illustrated in Figures 1 and 2.

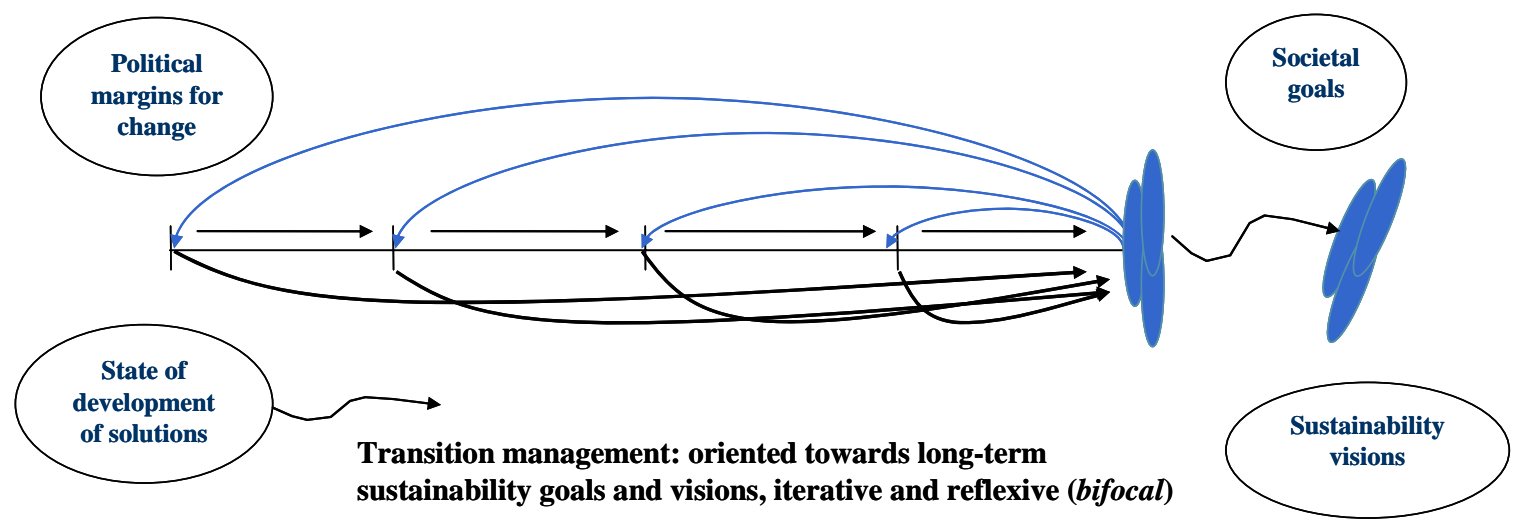

Figure 1. Feedback from long-term sustainability goals and visions to current decisionmaking (Source: Kemp and Loorbach, 2005)

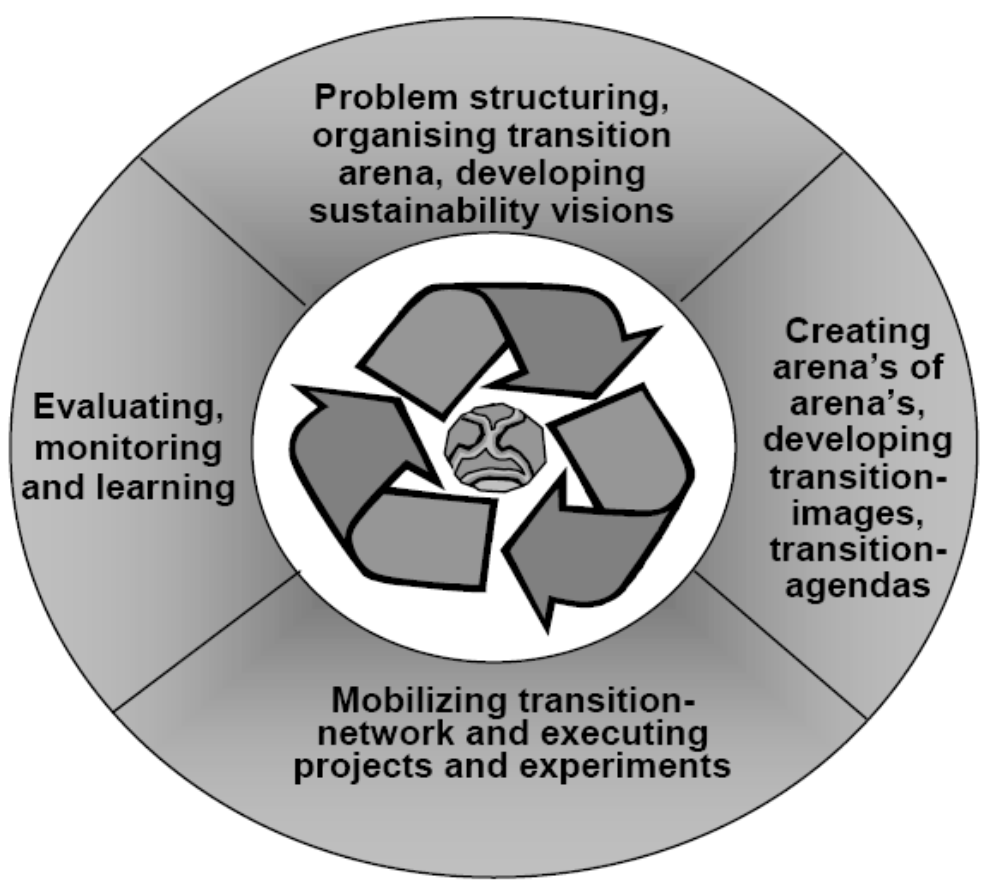

Figure 2. Iterative process of transition management (Source: Kemp and Loorbach, 2005)

However, though it has intuitive appeal, the transition approach has been criticised from a theoretical viewpoint for offering an overly functionalist and structural explanation, for example “... the tendency to treat regime transformation as a monolithic process dominated by rational action and neglecting important differences in context” (Smith et al., 2005, p.1492). It has also been criticised for downplaying the role of power-relations and agenda setting. In the practical application of transition management in the Netherlands, this has led to concerns that the transitions approach risks capture by the incumbent energy regime, thereby undermining the original NMP4 ambition for radical innovation of the energy system. This is 
exemplified by the fact that the energy transition taskforce, set up in 2005 to oversee the transition process and identify strategic directions, is chaired by the CEO of Shell Netherlands (Kern and Smith, 2007).

\section{The adaptive management and resilience approach}

Adaptive management is an approach that has rapidly expanded in its application over recent years (e.g. Berkes and Folke, 1998; Lee, 1999; Milestad and Hadatsch, 2003; Olsson et al., 2004). It has been used across a wide range of environmental contexts to inform the management of social-ecological systems including fisheries (McDaniels and Gregory, 2004; Pinkerton, 1999), agriculture (Tress and Tress, 2003), grasslands (Salwaser, 1999), forests (McGinley and Finnegan, 2003; Gray, 2000) and rangeland grazing (e.g. Clements, 2004). Rooted in Holling's studies of structural change and ecosystem functioning in the 1970s, early adaptive frameworks initiated a trend away from theories of equilibrium within the ecological sciences, towards an understanding of nature as a dynamic, self-organising system in continuous chaotic flux (Levin, 1992; Bavington, 2002). As this complexity has been more widely accepted, it has gradually led to the emergence of an adaptive management paradigm in which managers acknowledge the limits to predictability (Levin, 1999), and acceptance that knowledge about ecosystems is both uncertain and pluralistic (Carpenter and Gunderson, 2001). This in turn, has caused an emphasis being placed on learning, as interventions are strategically designed to allow hypotheses about the functioning of a system to be tested through experimentation (Holling, 1978; Walters, 1986; Clark et al., 2001). In this way, the results from one generation of experimentation and study inform subsequent decisions (Stringer et al., 2006). Adaptive management processes for a particular system thus start with the identification of system boundaries and system context, as well as both problems and the desired goal(s). Hypotheses and goals are then developed and tested. This leads to the implementation of policy strategies and monitoring of results (often using empirically tested indicators), after which the problem and goals are re-visited, and the cycle starts again. Figure 3 provides a graphical illustration of this cycle, which in this case, was developed to help stakeholders manage and monitor progress towards sustainability in the Kalahari (see Reed et al., 2006). 


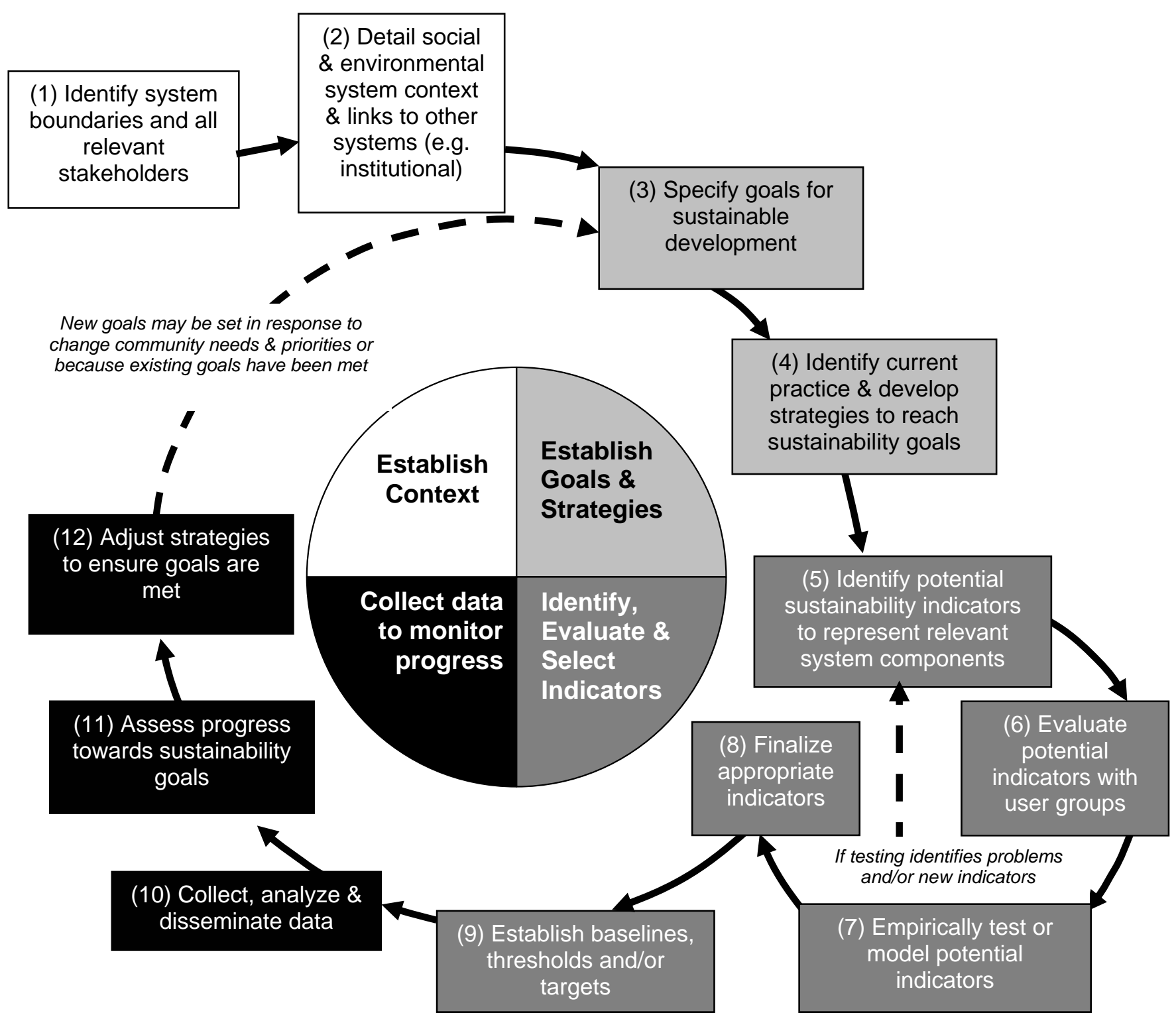

Figure 3. Illustrative adaptive management process, as followed by Reed et al. (2006) to help stakeholders manage and monitor progress towards sustainability in the Kalahari, Botswana.

In an adaptive management approach, system boundaries are often defined as a delineated spatial area (for example, a watershed, forest or river catchment). Drawing boundaries in this way can simultaneously encompass multiple spatial scales of operation of both social and ecological processes. Within those boundaries, a variety of stakeholders may be engaged, to help ensure policy reflects many different values and viewpoints (scientific, local and indigenous), not only in the exploration of a management 'problem', but also in goal setting, experimentation and management planning (McLain and Lee 1996; Johannes 1998, Ludwig et al., 2001; Folke, 2003). Recently, increasing critical attention has been paid to the social system boundaries and nature of stakeholder selection and involvement (e.g. Prell et al., 2008), as well as the ways in which participatory processes and information flows can enhance social learning and build adaptive capacity (see Stringer et al., 2006). This can sometimes lead adaptive management to be conceptualised as a polycentric style of governance, which does not have a single centre (Hooghe and Marks, 2003; Ostrom et al., 1961). 
Instead, a process of multi-level governance can be allowed to evolve within the system boundaries (Gatzweiler, 2005), permitting flexibility and interplay across scales. This approach takes into consideration ecological niches, economies of scale and stakeholder preferences across different, vertically-integrated levels of the system (Marks and Hooghe, 2005). However, in general, adaptive management remains tied to the operational level (Pahl-Wostl, 2007).

Similarly, time-scales play an important role within the adaptive management approach, largely because policies and goals are established over a particular timeframe, with monitoring and assessment and re-evaluation continuously taking place. The iterative nature of the adaptive cycle means that each stage offers the potential to involve different stakeholder groups and the opportunity for them to learn from each other (Walters, 1986). This results in the development of a social as well as scientific process, as communication and information can pass in multiple directions between multiple stakeholders at different times. In taking such an iterative, cyclical approach, management processes, institutions and policies can be adapted, as circumstances change, knowledge about the system is accrued and learning takes place. This shifts the emphasis from 'objective science' towards 'learning over time whilst managing'. Even if a system collapses, time remains important. Social-ecological memory (i.e. legacy) of the previous system state can persist, acting as a point of growth for renewal and reorganisation. Social memory endures in the individuals and institutions that store and use various practices and knowledges and hold different values and worldviews (Adger et al., 2005), while ecological memory refers to the environmental legacies following collapse, including the landscapes, colonising species and habitats that develop on disturbed sites (Berkes et al., 2003).

Closely linked to the adaptive management process are concepts of resilience. Holling originally introduced the notion of ecological resilience as a concept for understanding regime shift in the 1960s and 70s (Scheffer et al., 2001), through studies of predator-prey relationships in relation to ecological stability theories (Holling, 1961). The initial work on resilience focused on the buffering capacity of ecosystems to absorb shocks without collapsing into a different state, structure or function, controlled by a different suite of processes. The resilience of an ecosystem therefore refers to its ability to withstand shocks, maintain stability during disturbances and rebuild itself when required (Carpenter and Gunderson, 2001). In social systems, this extends to consider the social system's capability to self-organise and build capacity for learning and adaptation. Resilience can thus be enhanced through the maintenance of diversity, be it biological diversity that can compensate for the loss or gain of species, or multi-stakeholder involvement, which can draw on a wider knowledge base and potentially lead to better informed policy options. As such, concepts of resilience draw upon human capacities to iteratively experiment, learn, anticipate, plan for the future and manage risk. Nevertheless, it is not always possible to return a system to a previous (desired) state, particularly if threshold levels have been surpassed.

\section{Discussion: Comparison of the two frameworks}

The key characteristics of the adaptive management and socio-technical transitions frameworks are compared in Table 1. 
Table 1: Key characteristics of the Adaptive Management and Socio-Technical Transitions Frameworks

\begin{tabular}{|c|c|c|}
\hline Characteristic & $\begin{array}{l}\text { Adaptive management and } \\
\text { resilience framework }\end{array}$ & $\begin{array}{l}\text { Socio-technical transitions } \\
\text { framework }\end{array}$ \\
\hline Management style & $\begin{array}{l}\text { Actions are designed as experiments } \\
\text { through which learning is } \\
\text { encouraged in an iterative process of } \\
\text { management. Aims to build capacity } \\
\text { for both anticipatory and reactive } \\
\text { management allowing maintenance } \\
\text { of system functions in the face of } \\
\text { external changes. }\end{array}$ & $\begin{array}{l}\text { Process-oriented and goal- } \\
\text { seeking; learning from } \\
\text { experimentation in complex } \\
\text { systems; focuses on ability to } \\
\text { steer long-term changes in } \\
\text { functioning of system. }\end{array}$ \\
\hline Governance style & $\begin{array}{l}\text { Polycentric; horizontal, including } \\
\text { multiple stakeholders; sometimes } \\
\text { also vertical and diffuse (throughout } \\
\text { a network). }\end{array}$ & $\begin{array}{l}\text { Multi-level governance; } \\
\text { interactions between niche, } \\
\text { regime and landscape socio- } \\
\text { technical levels. }\end{array}$ \\
\hline $\begin{array}{l}\text { Scale of analysis \& } \\
\text { operation }\end{array}$ & $\begin{array}{l}\text { System boundaries often defined as } \\
\text { a delineated spatial area (e.g. } \\
\text { watershed or catchment). Often } \\
\text { encompasses multiple spatial scales. }\end{array}$ & $\begin{array}{l}\text { Focus on industrial sectors, e.g. } \\
\text { energy, water management, } \\
\text { fulfilling societal functions, e.g. } \\
\text { providing heating, lighting, clean } \\
\text { water, etc. }\end{array}$ \\
\hline $\begin{array}{l}\text { Information } \\
\text { management and } \\
\text { communication }\end{array}$ & $\begin{array}{l}\text { Combines one and two way } \\
\text { information flows between } \\
\text { stakeholders and analysts and can } \\
\text { include participatory processes } \\
\text { (particularly in monitoring and } \\
\text { assessment). }\end{array}$ & $\begin{array}{l}\text { Public-private process of goal- } \\
\text { setting informs transition paths } \\
\text { and experiments, involving } \\
\text { multiple stakeholders. }\end{array}$ \\
\hline Infrastructure & $\begin{array}{l}\text { Adaptive management is mainly } \\
\text { limited to the operational level } \\
\text { (Pahl-Wostl, 2007) although can } \\
\text { span several different levels through } \\
\text { polycentric governance and vertical } \\
\text { integration. }\end{array}$ & $\begin{array}{l}\text { Aim to operate at multiple levels } \\
\text { of decision-makings, i.e. } \\
\text { strategic as well as operational. }\end{array}$ \\
\hline Risk management & $\begin{array}{l}\text { Risk management in this framework } \\
\text { is closely linked to the maintenance } \\
\text { of diversity (be it biological } \\
\text { diversity or multiple-stakeholder } \\
\text { involvement). In turn, this is } \\
\text { informed through iterative learning, } \\
\text { experimentation and capacity } \\
\text { building to manage risks. }\end{array}$ & $\begin{array}{l}\text { Aim to take into account risk and } \\
\text { uncertainty by formulating } \\
\text { different possible transition } \\
\text { paths and learning-by doing in } \\
\text { transition experiments to assess } \\
\text { their social and technological } \\
\text { feasibility and acceptability. }\end{array}$ \\
\hline
\end{tabular}

Despite the use of different terminology and jargon, a number of similarities are present between the two frameworks. For example, adaptive management and transition management both have their roots in thinking which recognises the complexity of, and interactions between, social, economic and ecological systems (Holling, 1978; Hughes, 1983). (This has close links to more recent ideas on complex adaptive systems, though much of that work has focussed more on building computational models of such systems (Holland, 1995)). These approaches emphasise 
the evolutionary, path-dependent nature of change in such systems, and hence that the future dynamics of such systems are subject to risk and uncertainty, and so are inherently unpredictable. This implies that detailed control and management of these systems is impossible and so more flexible and responsive approaches are needed. This is in contrast to more reductionist approaches which seek to assess the optimal course of action based on an assessment of the estimated costs and benefits of future options, assuming quantifiable assessments of uncertainties.

The alternative philosophy proposed by both AM and TM is an iterative, learningbased approach to managing complex systems, characterised as "learning to manage by managing to learn” (Bormann et al., 1994; Pahl-Wostl, 2007). This is achieved through the application of repeated experimentation and revising of future directions based on learning from these experiments. They also both emphasise the involvement of a wide range of stakeholders in decision-making and the need for institutional changes to provide arenas for learning and adaptive decision-making. Both frameworks seek to reach sustainability goals that have been negotiated with stakeholders, though these goals tend to be longer-term aspirations in TM compared to the often shorter-term operational goals of AM. In both frameworks, these goals can be revised and refined as stakeholders learn about the socio-ecological system through the process of experimentation. However, as noted in Table 1 there are important differences of emphasis and context between the two approaches, which suggests the potential for mutual learning.

The AM approach starts from the need to build adaptive capacity within a socioecological system to enable maintenance of system functions and allay the risk of large-scale collapse, whereas TM focuses on developing the ability to steer long-term changes in functioning of socio-technical systems. In TM, innovation therefore acts as an important driver of regime change. However, innovation has the capacity to enhance adaptive capacity, and there is evidence that the combination of scientific and local knowledges that often occurs in AM projects can facilitate the development of innovative options for adaptive management (Reed et al., 2007, in press). In general though, the AM approach relies on the accretion of adaptive capacity in order to absorb and manage rather than direct change. TM also works at a sectoral level, e.g. energy, water management, and seeks to modulate change towards systems that fulfil societal functions, such as providing heating, lighting or clean water services, in more sustainable ways, e.g. by moving from current high-carbon energy regimes to future low-carbon energy regimes. This focus on long-term modulation of change could help to enhance the AM approach by considering not only resilience in the face of transitory external shocks, but also in response to more gradual changes in external environments and internal preferences. For instance, this may include the involvement of stakeholders in thinking about desired futures states of socio-ecological systems and what steps or paths would be needed to achieve these. Indeed, this type of approach is currently taking place in research in the uplands of the UK's Peak District National Park, where stakeholders and researchers are working together to anticipate, monitor and sustainably manage rural change (see Dougill et al., 2006). It is anticipated that the results from this study will identify the current needs and aspirations of stakeholders and inform the development of a choice of solutions to current challenges and potential pathways to desired futures that could never have been developed by either group alone. 
Evidence from AM processes suggests that multi-stakeholder input and participatory processes are crucial in building system resilience. The issue of costs and risks in AM is interesting however, and one that sits centrally in critiques of the AM approach. While short-term (substantial) investments are often needed to support experimentation and the participation of diverse interest groups, the returns from these investments may only be seen over the long-term. Where experimentation and opportunities for participation are restricted due to this tension, the costs of lostlearning is rarely accounted for. Despite these tensions, there is an increasingly rich tradition of stakeholder participation in AM. Drawing on collaborative management approaches, the participatory approach to AM is often referred to as "adaptive comanagement" (Ruitenbeek and Cartier, 2001; Olsson et al., 2004; Plummer and Armitage, 2006). Among the many claims for adaptive co-management, it is argued that participatory processes lead to higher quality decisions, as they can be based on more complete information, anticipating and ameliorating unexpected negative outcomes before they occur (Beierle, 2002). There is evidence to support this claim from a number of case studies (e.g. Brody, 2003; Koontz, 2005; Sultana and Abeyasekera, 2007). Stakeholder Analysis is also gaining prominence in adaptive comanagement as a way of systematically representing those relevant to environmental decision-making processes (Prell et al., in press; Reed et al., in prep.). Though TM aims to involve a wide range of stakeholders, as we saw above, it has been criticised for risking capture by dominant actors within existing regimes. More explicit use of multi-stakeholder and participatory processes within TM could help to avoid this outcome, better managing stakeholder relationships and power dynamics and giving more weight to those advocating the feasibility and desirability of different futures that threaten current interests.

Similarly, AM emphasises the role of diversity in building and maintaining the capacity to manage risks. Though multiple pathways are developed within TM, there has been little direct emphasis on the importance of diversity. Recent work on the role of diversity in maintaining and enhancing resilience within socio-technical systems for supplying energy services (Stirling, 2007) suggests that this could be an important area for future research.

Scale is an important consideration within AM, particularly when the socio-ecological system of interest crosses multiple scales. The experimental element of the AM approach means that it remains vulnerable to the inherent scale issues faced by experimental scientific research. For example, large-scale systems may exhibit properties that cannot be detected or perhaps do not even take place at smaller scales. Similarly, while some effects are too small to observe at the laboratory scale, they may nevertheless cause adverse effects when taking place in a larger system (Lee, 1993). This means that despite experimentation, managers taking an AM approach must recognise that experimental outcomes are closely linked to other scales and that the potential for experimental uncertainties remains high. There is also a time dimension to consider when thinking about scale. In AM, it is the results of experiments which provide the basis on which learning can take place. In TM, there is more emphasis on the longer term and the future. Additionally, the scale of focus is usually sector-specific in TM (e.g. energy, water etc), and the future goal is to move society as a whole towards a more sustainable energy or water system. This means that less emphasis is placed on the scale issue, but it is still important in the context of the extent to which experiments which are successful in niches can be scaled up to 
challenge dominant regimes, as demonstrated by the difficulties faced by attempts to diffuse experiments in sustainable transport solutions (Hoogma et al., 2002).

Perhaps the most interesting comparisons and contrasts between the two approaches come in relation to governance processes and institutional changes. As noted above, AM can be conceptualised as a polycentric style of governance, which does not have a single centre, but rather, a process of multi-level governance can be allowed to evolve within the system boundaries. However, the extent to which this can occur depends on broader governance contexts and a political system that is open to public participation in environmental decision-making, which form part of the landscape context in TM. TM makes use of a specific macro-meso-micro level framework, based on landscapes, regimes and niches. This framework could be seen as constraining but it has proved useful in analyzing a range of different transitions, and so its application to AM processes could be investigated, as suggested by Pahl-Wostl (2007).

Finally, both approaches recognize the need for changes to current institutions so that they are able to facilitate the type of long-term, iterative, learning-based and participatory approaches needed for the management of complex systems towards sustainability. Both approaches argue that neither top-down command-and-control management nor bottom-up free-market, laissez-faire processes are adequate in face of short-term and long-term challenges to the sustainability of current socioecological and socio-technical systems. Both AM and TM can be seen as attempts to create institutional frameworks to achieve positive change in complex multi-level and multi-stakeholder systems, in the face of severe risk and uncertainties. Despite the positive advances achieved by both approaches, creating such institutional frameworks remains elusive in practice. This may be because the requirements of both AM and TM processes are at variance with many of the institutional structures of the organisations charged with implementing environmental policy. For example, decision-makers may feel uncomfortable committing themselves to implement and resource the as-yet unknown outcome of an AM or TM process. In many cases, to do so would represent a radical shift in the organisational culture of government agencies and other institutions.

\section{Conclusion}

This paper has presented information on two frameworks that may be used to inform the development of strategies to address social-ecological change. Though usually applied in different domains, the frameworks share a number of similarities but also exhibit a number of differences. By exploring what the two frameworks could learn from each other, we hope that the ideas presented here can contribute to a fruitful ongoing dialogue between the two approaches, in order to foster more resilient and robust processes of governance to enhance the sustainability of socio-ecological and socio-technical systems.

\section{References}

Adger, W. N., Hughes, T. P., Folke, C., Carpenter, S. R. and Rockström, J. 2005. Social-ecological resilience to coastal disasters, Science 309 (2005), pp. 1036-1039.

Bavington, D. 2002. Managerial ecology and its discontents: exploring the complexities of control, careful use and coping in resource and environmental management. Environments 30: 3-21. 
Beierle, T.C. 2002. The quality of stakeholder-based decisions, Risk Analysis 22: 739-749

Berkes, F., and Folke, C. 1998 Linking Social and Ecological Systems Cambridge University Press, Cambridge, UK.

Berkes. F., J. Colding, and C. Folke. 2003. Navigating social-ecological systems: building resilience for complexity and change. Cambridge University Press, Cambridge, UK.

Bormann BT, Cunningham PG, Brookes MH, Manning VW, Collopy MW (1994) Adaptive ecosystem management in the Pacific Northwest. USDA For. Serv. Gen. Tech. Rep. PNWGTR-341. 22 pages

Bossel, H. 1998. Earth at a Crossroads: Paths to a Sustainable Future. Cambridge University Press, Cambridge.

Bossel, H. 2001. Assessing viability and sustainability: a systems-based approach for deriving comprehensive indicator sets. Conservation Ecology 5, 12 (online).

Brody, S.D. 2003. Measuring the effects of stakeholder participation on the quality of local plans based on the principles of collaborative ecosystem management, Journal of Planning Education and Research 22: 407-419.

Brock , A. W., and Carpenter, S. R., 2007. Panaceas and diversification of environmental policy. PNAS 104 (9) 15206-15211.

Carpenter, S. R., and L. H. Gunderson. 2001. Coping with collapse: ecological and social dynamics in ecosystem management. BioScience 51:451-457.

Clark, W. C., Jager, J., van Eijndhoven, J, and Dickson, N. 2001. Learning to Manage Global Environmental Risks: A Comparative History of Social Responses to Climate Change, Ozone Depletion, and Acid Rain, MIT Press, Cambridge, MA.

Clements, A. 2004. An ecosystem approach to combat desertification on the Colorado Plateau. Environmental Monitoring and Assessment 99: 233-243.

Dougill, A.J.; Fraser, E.D.G.; Holden, J.; Hubacek, K.; Prell, C.; Reed, M.S.; Stagl, S.; Stringer, L.C. 2006. Learning from Doing Participatory Rural Research: Lessons from the Peak District National Park, Journal of Agricultural Economics, 57, pp.259-275

Folke, C. 2003. Social-Ecological Resilience and Behavioural Responses. Pages 226-242 in A. Biel, B. Hansson and M. Mårtensson, editors. Individual and Structural Determinants of Environmental Practice. Ashgate Publishers, London, UK.

Gatzweiler F 2005 Central and Eastern European Agriculture and Environment: The Challenge of Governance at Multiple Levels. Sociologia Ruralis, 45 (3): 139-152.

Gray, A. N. 2000. Adaptive ecosystem management in the Pacific Northwest: a case study from coastal Oregon. Conservation Ecology 4(2): 6. [online] URL: http://www.consecol.org/vol4/iss2/art6/

Geels, F. W. (2002). Technological Transitions and System Innovations: A Co-evolutionary and SocioTechnical Analysis, Edward Elgar, Cheltenham, UK

Holland, J.H. 1995. Hidden Order: How Adaptation Builds Complexity, Perseus Books, Cambridge, MA

Holling, C. S. 1961. Principles of insect predation, Annual Review of Entomology 6 (1961), pp. 163182.

Holling, C. S. 1978. Adaptive environmental assessment and management. Wiley, New York, USA.

Hooghe L and Marks G 2003. Unravelling the central state, but how? Types of multi-level governance. American Political Science Review 97, 233-243.

Hoogma, R., Kemp, R., Schot, J. and Truffler, B. 2002. Experimenting for Sustainable Transport: The approach of Strategic Niche Management. Spon Press, London.

Hughes, T.P. 1983. Networks of Power: Electrification in Western Society, 1880-1930. Johns Hopkins University Press, Baltimore

Inter-governmental Panel on Climate Change (IPCC) 2007. Climate Change 2007: Fourth Assessment Report, Cambridge University Press

Janssen MA and Ostrom E 2006 Resilience, Vulnerability, and Adaptation: A Cross-Cutting Theme of the International Human Dimensions Programme on Global Environmental Change. Global Environmental Change 16 (3) 237-239.

Johannes, R. E. 1998. The case of data-less marine resource management: examples from tropical nearshore finfisheries. Trends in Ecology and Evolution 13:243-246.

Kemp, R. and J. Rotmans 2005. The management of the co-evolution of technical, environmentaland social systems, in Matthias Weber and Jens Hemmelskamp (eds) Towards Environmental Innovation Systems, Berlin: Springer Verlag. 
Kemp, R. and D. Loorbach 2005, Dutch policies to manage the transition to sustainable energy. In F. Beckenbach (ed.). Jahrbuch Ökologische Ökonomik 4 Innovationen und Nachhaltigkeit, MetropolisVerlag, Marburg, 123-150.

Koontz, T.M. 2005. We Finished the Plan, So Now What? Impacts of Collaborative Stakeholder Participation on Land Use Policy. The Policy Studies Journal 33: 459-481.

Lee, K.N. 1993. Compass and gyroscope: integrating science and politics for the environment. Washington, DC: Island Press. 243 p.

Lee, K. N. 1999. Appraising adaptive management. Conservation Ecology 3(2): 3. [online] URL: http://www.consecol.org/vol3/iss2/art3/

Levin, S. A. 1992. The problem of pattern and scale in ecology. Ecology 73:1943-1967.

Levin, S. 1999. Fragile Dominion. Perseus Books, Reading, MA, USA.

Loorbach, D. and J. Rotmans 2006. Managing Transitions for Sustainable Development. Understanding Industrial Transformation. Views from Different Disciplines. X. Olsthoorn and A. J. Wieczorek. Dordrecht, Springer: 187-206.

Ludwig, D., M. Mangel, and B. Haddad. 2001. Ecology, conservation, and public policy. Annual Review of Ecology and Systematics 32:481-517.

Marks G and Hooghe L 2005. Contrasting visions of multi-level governance. In: Bache I and Flinders M (eds) Multi-level Governance. Oxford University Press, Oxford. pp. 15-30.

McDaniels, T. L., and R. Gregory. 2004. Learning as an objective within a structured risk management decision process. Environmental Science and Technology 38: 1921-1926.

McGinley, K., and B. Finegan. 2003. The ecological sustainability of tropical forest management: evaluation of the national forest management standards of Costa Rica and Nicaragua, with emphasis on the need for adaptive management. Forest Policy and Economics 5: 421-431.

Mc Lain, R. J., and R. G. Lee. 1996. Adaptive management: pitfalls and promises. Environmental Management 20: 437-448.

Milestad R and Hadatsch S 2003 Organic farming and social-ecological resilience: the alpine valleys of Sölktäler, Austria. Conservation Ecology 8(1): 3. Online: http://www.consecol.org/vol8/iss1/art3/

Ministry of Economic Affairs (The Netherlands) 2006. More with Energy: Opportunities for the Netherlands, Energy Transition Action Plan. Online: http://www.senternovem.nl/energytransition/downloads/index.asp

Nagendra H 2007. Drivers of reforestation in human-dominated forests. PNAS 104 (39) 15218-15223.

OECD 1993. OECD Core Set of Indicators for Environmental Performance Reviews. A Synthesis Report by the Group on the State of the Environment. Organisation for Economic Cooperation and Development, Paris.

Olsson P, Folke C and Berkes F 2004. Adaptive co-management for building resilience in socialecological systems. Environmental Management 34:75-90

Ostrom V, Tiebout, CM and Warren R 1961. The organization of government in metropolitan areas: a theoretical inquiry. American Political Science Review 55: 831-842.

Ostrom E 2007 A Diagnostic approach for going beyond panaceas. PNAS 104 (39):15181-15187.

Ostrom E., Janssen, M.A, and Anderies, J. M. 2007. Going beyond panaceas. PNAS 104 (39): 15176-15178.

Pahl-Wostl C. 2007 Transitions towards adaptive management of water facing climate and global change. Water Resources Management 21:49-62

Pinkerton, E. 1999. Factors in overcoming barriers to implementing co-management in British Columbia salmon fisheries. Conservation Ecology 3(2): 2. [online] URL: http://www.consecol.org/vol3/iss2/art2/

Plummer, R. and Armitage, D. 2006. A resilience-based framework for evaluating adaptive comanagement: Linking ecology, economy and society. Ecological Economics.

Prell C, Reed MS and Hubacek K in press. Social network analysis and stakeholder analysis for natural resource management. Society \& Natural Resources

Reed M.S.; Fraser, E.D.G.; Dougill, A.J. 2006 An adaptive learning process for developing and applying sustainability indicators with local communities, Ecological Economics, 59, pp.406418.

Reed, M.S., Dougill, A.J. and Taylor, M.J. 2007. Integrating local and scientific knowledge for adaptation to land degradation: Kalahari rangeland management options. Land Degradation \& Development 18: 249-268.

Reed, M.S., Dougill, A.J. and Baker, T. in press. Participatory indicator development: what can ecologists and local communities learn from each other? Ecological Applications 
Rip, A. and Kemp, R. 1998. Technological change, in Human Choices and Climate Change, Vol. 2, ed. S. Rayner and E.L. Malone, Battelle Press, Columbus, Ohio

Rotmans, J., R. Kemp and M. van Asselt 2001b. More evolution than revolution: transition management in public policy. Foresight 3: 15-31.

Ruitenbeek, J. and Cartier, C. 2001. The Invisible Wand: Adaptive Co-Management as an Emergent Strategy in Complex Bio-economic Systems. Occasional Paper No. 34. Centre for International Forestry Research, Bogor, Indonesia.

Scoones, I. 1998. Sustainable rural livelihoods: a framework for analysis. IDS Working Paper 72, Institute of Development Studies, Brighton.

Sultana, P. and Abeyasekera, S. 2007. Effectiveness of participatory planning for community management of fisheries in Bangladesh, Journal of Environmental Management 86: 201-213.

van der Brugge, R., and R. van Raak. 2007. Facing the adaptive management challenge: insights from transition management. Ecology and Society 12(2): 33. [online] URL: http://www.ecologyandsociety.org/vol12/iss2/art33/

Salwasser, H. 1999. Ecosystem Management: A New Perspective for National Forests and Grasslands. Pages 85-96 in J. Aley, W. R. Burch, B. Conover, and D. Field, editors. Ecosystem Management: Adaptive strategies for natural resource organisations in the 21st century. Taylor and Francis, USA.

Scheffer, M., S. A. Carpenter, J. A. Foley, C. Folke, and B. Walker. 2001. Catastrophic shifts in ecosystems. Nature 413:591-596.

Stirling, A 2007. Resilience, Robustness, Diversity: dynamic strategies for sustainability, Paper presented at European Society for Ecological Economics Conference, Leipzig, June 2007

Stringer, L. C., A. J. Dougill, E. Fraser, K. Hubacek, C. Prell, and M. S. Reed. 2006. Unpacking "participation" in the adaptive management of social-ecological systems: a critical review. Ecology and Society 11(2): 39. [online] URL: http://www.ecologyandsociety.org/vol11/iss2/art39/

Tress, B., and G. Tress. 2003. Scenario visualisation for participatory landscape planning- a study from Denmark. Landscape and Urban Planning 64: 161-178.

Walker, B. H., Holling, C. S., Carpenter, S. R. and Kinzig, A. P. 2004. Resilience, adaptability and transformability in social-ecological systems, Ecology and Society 9 (2004) (2), p. 5 [online] URLhttp://www.ecologyandsociety.org/vol9/iss2/art5/

Walters, C. J. 1986. Adaptive management of renewable resources.; McMillan, New York, New York, USA. 